\title{
LRP-1: A Checkpoint for the Extracellular Matrix Proteolysis
}

\author{
Nicolas Etique, Laurie Verzeaux, Stéphane Dedieu, and Hervé Emonard \\ CNRS FRE 3481 MEDyC (Matrice Extracellulaire et Dynamique Cellulaire), Laboratoire SiRMa (Signalisation et Récepteurs \\ Matriciels), Université de Reims Champagne-Ardenne (URCA), Moulin de la Housse, Bât. 18, Chemin des Rouliers, BP 1039, \\ 51687 Reims Cedex 2, France
}

Correspondence should be addressed to Hervé Emonard; herve.emonard@univ-reims.fr

Received 15 May 2013; Accepted 20 June 2013

Academic Editor: Davide Vigetti

Copyright (C) 2013 Nicolas Etique et al. This is an open access article distributed under the Creative Commons Attribution License, which permits unrestricted use, distribution, and reproduction in any medium, provided the original work is properly cited.

\begin{abstract}
Low-density lipoprotein receptor-related protein-(LRP-1) is a large endocytic receptor that binds more than 35 ligands and exhibits signaling properties. Proteinases capable of degrading extracellular matrix (ECM), called matrix proteinases in this paper, are mainly serine proteinases: the activators of plasminogen into plasmin, tissue-type (tPA) and urokinase-type (uPA) plasminogen activators, and the members of the matrix metalloproteinase (MMP) family. LRP-1 is responsible for clearing matrix proteinases, complexed or not with inhibitors. This paper attempts to summarize some aspects on the cellular and molecular bases of endocytic and signaling functions of LRP-1 that modulate extra- and pericellular levels of matrix proteinases.
\end{abstract}

\section{Introduction}

Extracellular matrix (ECM) remodeling occurs in both physiological and pathological situations [1]. Tissue homeostasis depends on a strict equilibrium between synthesis and degradation of ECM macromolecules. In contrast, fibrotic pathologies are classically related to a defect or an increased ECM breakdown, while an excessive proteolytic degradation is the hallmark of inflammatory processes or tumor invasion. Numerous proteolytic enzymes are able to degrade ECM macromolecules, including the serine proteinases tissue-type plasminogen activator (tPA) and urokinase-type plasminogen activator (uPA) [2] and the members of the matrix metalloproteinase (MMP) family [3].

A series of specific or nonspecific inhibitors controls the activities of these powerful catalytic enzymes. Thus, the pan-protease inhibitor $\alpha 2$-macroglobulin $(\alpha 2 \mathrm{M})$ binds to and inhibits active members of the four classes of proteolytic enzymes [4]. More specifically, the serine proteinase inhibitors (serpins) and the plasminogen activator inhibitors (PAI) 1 and 2 block the activity of tPA and uPA [5]. Tissue inhibitors of metalloproteinases (TIMPs) inhibit the activity of MMPs [6] and also of adamalysins (a disintegrin and metalloproteinases, ADAMs) [7]. Besides this level of control, receptor-mediated endocytosis is an emergent and efficient biological mechanism to regulate extra- or pericellular levels of proteolytic enzymes by internalizing them for catabolism in lysosomes [8]. This paper briefly describes the main molecules involved in these events and reviews the different roles of low-density lipoprotein (LDL) receptorrelated protein-(LRP-1) in controlling extracellular matrix remodeling.

\section{Plasminogen Activators and Their Inhibitors}

Urokinase-type plasminogen activator (uPA) and tissue-type PA (tPA) are serine proteinases that catalyze the conversion of the zymogen plasminogen to the active serine proteinase plasmin [9]. Plasmin degrades numerous ECM macromolecules including laminin, fibronectin, and proteoglycans, triggers the activation of pro-MMPs, and activates or releases growth factors from ECM including latent-transforming growth factor $\beta$ and vascular endothelial growth factor. Both $\alpha 2 \mathrm{M}$ and the serpin $\alpha 2$-antiplasmin inhibit its activities [10]. Pro-uPA is synthesized as a one-chain molecule that is cleaved at a single peptide bond (K158-I159 in human uPA) by various proteases including plasmin to give active two-chain uPA of $55 \mathrm{kDa}$. Human $\mathrm{tPA}$ was first purified as 
a single-chain form of approximately $70 \mathrm{kDa}$. A limited attack of the R275-I276 bond by plasmin generates a two-chain tPA. The plasminogen activation activity of single-chain tPA is 10to 50-fold lower than that of the two-chain form [2]. The PA inhibitors PAI-1 and PAI-2 efficiently inhibited tPA and uPA catalytic activities [11].

The binding of uPA to its cell-surface receptor ( $\mathrm{UPAR}$ ) increases the affinity of UPAR for vitronectin and integrins, thus promoting cell adhesion, [12]. Interestingly enough by disrupting these interactions, PAI-1 detaches cells not only from vitronectin but also from fibronectin and collagen matrices [13]. This deadhesive property exhibited by PAI-1 could explain, at least partly, why paradoxically PAI-1 appears to be essential for cancer cell invasion and angiogenesis [14].

\section{Matrix Metalloproteinases and Their Inhibitors}

MMPs are the major matrix-degrading proteases due to the wide variety of their substrates and their role in numerous physiopathological processes $[15,16]$. They belong to a large family of zinc-dependent endopeptidases. In humans, MMPs are represented by 23 members divided into two groups based on their localization (secreted or membrane-bound) or in five groups based on their domain organization and their substrate preference (collagenases, gelatinases, stromelysins, matrilysins, and membrane-type) [3,17]. The general structure of MMPs consists in three domains that are common to almost all MMPs: the prodomain of about 80 amino acids, the catalytic metalloproteinase domain of about 170 amino acids, and the hemopexin domain of about 200 amino acids (except for MMP-7, -26, and -23). MMPs are secreted as a proenzyme, an enzymatically inactive state that results from the interaction between the "cysteine switch" motif in the prodomain and the zinc ion of the catalytic site [18]. The activation of these zymogens is an important regulatory step of MMP activity and occurs after the disruption of this interaction [15]. This process requires the proteolytic removal of the pro-domain by intracellular convertases such as furin or by extracellular proteinases (MMPs, plasmin, ..., etc.). A chemical perturbation of the cysteine-zinc interaction by $\mathrm{SH}$ reagents, by chaotropic agents (in vitro), or by antioxidant has been shown as sufficient to activate proMMPs [18].

After their activation, MMPs are regulated by two major types of endogenous inhibitors: $\alpha 2 \mathrm{M}$ and TIMPs [18]. $\alpha 2 \mathrm{M}$ is a plasma glycoprotein produced in the liver. Four nearly identical, disulfide-bonded domains of $180 \mathrm{kDa}$ compose this $772 \mathrm{kDa}$ protein. Inhibition mechanism involves the presentation of a cleavable region that, once proteolytically cleaved, induces a conformational change entrapping the proteinase that becomes covalently anchored by transacylation. Such a molecular complex is rapidly cleared by LRP-1-mediated endocytosis [19].

TIMPs are 184-194 amino acid proteins that have been described to form 1:1 stoichiometric complexes with active MMPs leading to the inhibition of their proteolytic activity. Four TIMPs (TIMP-1, -2, -3, and -4) have been identified in humans, inhibiting all MMPs tested so far, except TIMP-1 that was reported as being a poor inhibitor for MT1-MMP, MT3MMP, MT5-MMP, and MMP-19 [6, 18, 19]. All structurally characterized inhibitory TIMP-metalloproteinase complexes are closely similar. Within the metalloproteinase active site, the catalytic zinc atom is chelated by the N-terminal amino group and the carbonyl group of cysteine 1 [20]. TIMPs are also able to interact with proMMPs: TIMP-2, TIMP-3 or TIMP- 4 with proMMP-2 and TIMP-1 or TIMP-3, with proMMP-9 [20]. These complexes are stabilized by interaction between the TIMP C-terminal domain and hemopexin domain of the zymogen. Since these interactions do not involve the N-terminal domain of the TIMP, such molecular complexes are capable of interacting with a second MMP molecule. Except for the role of proMMP-2-TIMP-2 in the MT1-MMP-mediated activation of proMMP-2 [21], their functional significance remains unclear [20].

More recently, TIMPs have been reported to induce various biological processes (cell survival, differentiation, epithelial-mesenchymal transition, ..., etc.) independently from their MMP-inhibitory activity [22, 23]. These effects involved an interaction with specific cell-surface receptors leading to signaling pathway activation. For example, TIMP-1 promotes cell survival in erythroleukemic cells after binding with a CD44/proMMP-9 complex receptor $[24,25]$ and in breast and lung epithelial cells after interacting with a CD63/integrin- $\beta 1$ complex receptor $[26,27]$.

\section{Low-Density Lipoprotein Receptor-Related Protein-1}

4.1. General Features. LRP-1 is the first member of a receptor family related to the LDL receptor [28]. The receptor for $\alpha 2 \mathrm{M}$-proteinase complexes [29] and CD91, which interacts with heat-shock proteins at the surface of antigen-presenting cells [30], corresponds to LRP-1. It is synthesized as a single-chain molecule processed by furin in the trans-Golgi compartment into a $515 \mathrm{kDa} \alpha$-chain and an $85 \mathrm{kDa} \beta$-chain which remain non-covalently associated the cell surface [8]. The extracellular $\alpha$-chain contains four basic amino acid residue-rich domains that interact with a number of ligands including proteins involved in lipoprotein metabolism, ECM proteins, growth factors, proteinases, and proteinaseinhibitor complexes. The transmembrane $\beta$-chain contains a cytoplasmic tail of 100 amino-acid residues including two NPxY motifs, necessary to trigger endocytosis and capable of interacting with many adaptors and signaling proteins.

The endocytic clearance of various ligands and signaling properties confer a main role to LRP-1 in a variety of pathophysiological processes including lipid metabolism, neurodegenerative diseases, blood-brain-barrier integrity, atherosclerosis, and cancer [8]. The importance of LRP-1 is confirmed by the lethality of mice carrying LRP-1 gene deletion at an early stage of embryonic development [31].

4.2. Endocytic Function. The LRP-1-mediated endocytic internalization of active proteinases linked to the panproteinase inhibitor $\alpha 2 \mathrm{M}$ represents a general process to eliminate the excess of active proteinases from cellular 
TABLE 1: Main matrix proteinases and specific inhibitors known to bind to LRP-1.

\begin{tabular}{|c|c|c|}
\hline Serine proteinases, serpi & and serine $\mathrm{p}$ & teinase/serpin complexes \\
\hline $\begin{array}{l}\text { tPA } \\
\text { (pro)uPA }\end{array}$ & PAI-1 & $\begin{array}{c}\text { tPA, uPA/PAI-1 } \\
\text { uPA/PAI-2 }\end{array}$ \\
\hline MMPs, TIM & and $\mathrm{MMP} / \mathrm{T}$ & IP complexes \\
\hline (pro)MMP-2/TSP-1, -2 & TIMP-1 & IMP $2 /$ TIMP \\
\hline (pro)MMP-9 & TIMP-2 & (pro)MMP-9/TIMP-1 \\
\hline (pro)MMP-13 & TIMP-3 & \\
\hline Otl & matrix prote & ases \\
\hline Heparanase precursor & & \\
\hline Procathepsin-D & & \\
\hline ADAMTS-5 & & \\
\hline
\end{tabular}

environment $[19,32]$. Here, we review additional LRP-1mediated endocytosis that occurs independently from $\alpha 2 \mathrm{M}$ to regulate extracellular proteinase activities (Table 1).

4.2.1. Serine Proteinases and Inhibitors. The binding of tPA to cell surface has first been described through PAI-1-dependent [33] and PAI-1-independent [34] receptors. These receptors have been rapidly identified as being LRP-1 $[35,36]$. Orth and colleagues [37] confirmed that tPA, under its free form or complexed to PAI-1, binds to LRP-1 to be intracellularly degraded. Also, LRP-1 was shown to mediate the internalization of uPA associated to PAI-1 [31,38] and PAI-2 [39]. ProuPA binds to purified LRP-1 with affinity 15 to 20 fold, weaker than that of the uPA/PAI-1 complex [40]. In contrast, PAI-1 was described to interact with LRP-1 with high affinity when associated with proteinases [41]. These data strongly suggest that the binding of proteinase to PAI-1 could modify PAI-1 conformation, revealing a cryptic high-affinity binding site for LRP-1.

Besides its ability to link to LRP-1 to be internalized [40], pro-uPA is activated upon binding to UPAR [42]. Interestingly, both uPAR endocytosis and uPA catabolism are dependent on PAI-1 [43]. These important data support the role of LRP-1 in promoting the cell-surface PA activity by facilitating the clearance of uPA/PAI-1-occupied UPAR and the regeneration of unoccupied UPAR at the cell surface $[44,45]$. Such a process requires a direct binding between uPAR and LRP-1 [46]. This cycle of binding uPA/PAI-1 to UPAR followed by association with LRP-1, internalization, and intracellular dissociation and recycling of unoccupied UPAR and free LRP-1 to the cell surface can explain, at least in part, the promigratory effect of PAI-1 observed in invasive cells [47].

4.2.2. Matrix Metalloproteases and Inhibitors. In addition to its effect on UPA and tPA activities, LRP-1 also regulates extracellular levels of MMP-2, -9, and -13 [48]. As for uPA and tPA, the endocytosis of MMP-2 and MMP-13 involves preliminary binding to adjacent receptors. Indeed, when bound to thrombospondin-2 (TSP-2), proMMP-2 first associates with an unknown cell-surface heparin-sulfate proteoglycan before interacting with LRP-1 [49]. When complexed with its specific inhibitor TIMP-2, proMMP-2 first binds to an unidentified coreceptor before being internalized by LRP-1 [50]. Likewise, the endocytic clearance of MMP-13 by LRP-1 requires a two-step process, involving a first binding to a $170 \mathrm{kDa}$ coreceptor [51]. The internalization of MMP-9 by LRP-1 requires a more simple mechanism. Thus, proMMP-9/TIMP-1 directly interacts with LRP-1, leading to its endocytic uptake and degradation by lysosomal proteases [52]. The analysis of this interaction reveals that the hemopexin domain of MMP-9 contains a binding site for LRP-1 [53].

Although Hahn-Dantona et al. failed to demonstrate a direct interaction between TIMP-1 and LRP-1 in their in vitro study [52], our unpublished data reveal that LRP-1 could bind and endocytose TIMP-1 in neurons, in an MMP-independent way. Furthermore, noncomplexed TIMP-2 [50] and TIMP-3 $[54,55]$ also bind directly to LRP-1 to be internalized.

4.2.3. Other Matrix Proteinases. Heparanase-1 is secreted as an inactive heparanase precursor. Once activated, this endoglycosidase degrades heparan sulfate and consequently alters the stability of ECM [56]. The group of Guido David [57] has clearly identified LRP-1 as one of the receptors able to mediate the uptake of secreted heparanase precursor and its intracellular trafficking to the site of activation process. Recently, ADAM with thrombospondin motifs 5 (ADAMTS5), a major aggrecan-degrading enzyme in cartilage, has been shown to be endocytosed by LRP-1 [58].

The aspartic proteinase cathepsin-D (cath-D) is capable of degrading ECM in an acidic microenvironment [59]. Recently, Liaudet-Coopman and colleagues $[60,61]$ identified pro-cath-D as the first ligand of the extracellular domain of LRP-1 $\beta$-chain.

4.3. Signaling Function. Additionally, LRP-1 acts in signaling pathways $[8,28,62]$. We recently demonstrated that the abrogation of LRP-1 expression inhibited migration and invasive capacities of thyroid carcinoma cells despite a strong stimulation of pericellular MMP-2 and UPA proteolytic activities [63]. We identified ERK and JNK as the main molecular relays by which LRP-1 regulates focal adhesion disassembly of malignant cells to support invasion [64].

A stimulating study reveals that LRP-1-mediated endocytosis of tPA and tPA/PAI-1 complex is accompanied by a decrease in TPA mRNA transcription [65], suggesting that a secreted protein could regulate its own biosynthesis. Furthermore, the binding of tPA to LRP-1 triggers intracellular signal transduction to induce the expression of another matrix proteinase, MMP-9, both in microvascular endothelial cells [66] and fibroblasts [67]. Probably more surprising, the binding of proteinase inhibitors to LRP-1 also induces MMP-9 expression, as demonstrated for the serpin nexin1 in a mammary tumor model [68], and activate $\alpha 2 \mathrm{M}$ in macrophage-derived cell lines [69]. Recently, the knockdown of LRP-1 expression in human glioblastoma U87 cells revealed that LRP-1 promoted cell migration and invasion by inducing the expression of MMP-2 and MMP-9 [70]. 
Altogether, these data indicate a close link between MMP9 and LRP-1: from one of its ligands to a product of LRP1-induced expression. This suggests important functions for MMP-9 in normal and pathophysiological conditions.

4.4. Regulation of LRP-1 Cell-Surface Level and Endocytic Activity by Shedding. Most membrane proteins, including type I and type II transmembrane proteins, are subjected to a shedding process, that is, the proteolytic cleavage of their extracellular part or ectodomain [71]. LRP-1 also constitutes a membrane target for numerous proteinases. The LRP1 ectodomain consists in the entire extracellular $\alpha$-chain $(515 \mathrm{kDa})$ noncovalently associated to the extracellular part $(55 \mathrm{kDa})$ of the transmembrane $\beta$-chain [72].

The product of LRP-1 shedding, the soluble LRP-1 (sLRP1) $\alpha$-chain, was first detected in human plasma and serum [73]. A metalloproteinase, cleaving LRP-1 at the membraneproximal region of the $\beta$-chain, was described in human BeWo choriocarcinoma cells [72]. Since this work was completed, different metalloproteinases have been identified, mainly among the ADAM family. Thus, ADAM-10 and ADAM-17 are associated to LRP-1 shedding in human brain [74]. We recently showed that ADAM-12 exhibited sheddase activity towards LRP-1 in human HT1080 fibrosarcoma cells [75]. Additionally, we reported that MT-MMP, first described to degrade LRP-1 in small fragments [76], was able to generate sLRP-1 in medium conditioned by HT1080 cells in culture [75]. Besides these metalloproteinases, tPA and BACE-1 were described to mediate shedding of LRP-1 [77, 78]. It has been reported that, during cerebral ischemia, tPA induces the shedding of LRP-1 from perivascular astrocytes followed by the development of cerebral edema [79]. These authors demonstrated that the interaction between tPA and LRP1 in perivascular astrocytes induced Akt phosphorylation, leading to an increase of permeability in the blood-brain barrier.

Soluble LRP-1, which is composed of the entire extracellular $\alpha$-chain and noncovalently associated extracellular part of the transmembrane $\beta$-chain [72], retains ligand-binding capacity and acts as a decoy receptor [80]. Thus, Quinn and colleagues first reported that the addition of SLRP-1 to cultured rat hepatocytes resulted in an inhibition of tPA clearance [73]. Immunoprecipitation assays confirmed that tPA interacted with LRP-1 [72]. Also, LRP-1 shedding from human lung fibroblasts impairs endocytosis of MMP-2 and -9 [81]. We similarly reported that the inhibition of LRP1 shedding increased MMP-2 and -9 activities, in cultures of human endometrial explants [82] and fibrosarcoma cells [75]. Finally, we recently demonstrated that TIMP-3 bound to sLRP-1, which is resistant to endocytosis, retained its inhibitory activity against metalloproteinases [55].

\section{Conclusion}

Understanding the precise role of LRP-1 in the regulation of ECM breakdown remains an exciting challenge, as it appears to be a multifunctional "Swiss knife." Thus, besides the endocytosis of proteinases, LRP-1 mediates the clearance of their own inhibitors [8]. Moreover, LRP-1 acts as a membrane receptor that transduces intracellular signals to induce the MMP-9 expression [66-69]. Finally, the proteolytic cleavage of LRP-1 at the cell surface solubilizes the LRP-1 ectodomain, which conserves ligand-binding capacities. Such a property could allow matrix proteinases-but also inhibitors-to increase their extracellular half-life time by escaping from endocytic clearance mediated by membrane-LRP 1 .

Despite a strong stimulation of pericellular MMP-2 and uPA proteolytic activities, carcinoma cell invasion decreased by LRP-1 silencing [63]. This result clearly indicates that, depending on parameters yet to be elucidated, the signaling function of LRP-1 can counteract or override its endocytic function.

Another paradox is represented by a proteinase, tPA, for instance, which can either be endocytosed by LRP-1 or solubilize the ectodomain of LRP-1. At the molecular level, interactions between TPA and LRP-1 will be different according to the event: binding to domains 2 and 4 of the LRP-1 $\alpha$-chain for endocytic pathway or cleaving at a single site of both $\alpha$-and $\beta$-chains at the vicinity of the cell surface for shedding LRP-1 ectodomain. Which is determinant the enzyme or the cell?

On the whole, these data strongly suggest that LRP1 does not act alone but with membrane partners, which vary according to numerous parameters including cell origin, ECM composition, pathological conditions, and so forth. In this way, we recently demonstrated [83] that LRP-1 forms complex with the hyaluronan receptor CD44, which may bind proMMP-9 [24]. The identification of these partners could represent a key to the understanding of the LRP-1 roles in ECM remodeling.

\section{Acknowledgments}

The authors thank Claude-Annie Turlier for editorial assistance. They are supported by the Université de Reims Champagne-Ardenne and the Centre National de la Recherche Scientifique (CNRS), France. They acknowledge support from the Agence Nationale pour la Recherche (ANR08-MNPS-042-02, TIMPAD project). Laurie Verzeaux and Stéphane Dedieu were recipients of grants from the Région Champagne-Ardenne.

\section{References}

[1] P. Lu, V. M. Weaver, and Z. Werb, "The extracellular matrix: a dynamic niche in cancer progression," Journal of Cell Biology, vol. 196, no. 4, pp. 395-406, 2012.

[2] P. A. Andreasen, R. Egelund, and H. H. Petersen, “The plasminogen activation system in tumor growth, invasion, and metastasis," Cellular and Molecular Life Sciences, vol. 57, no. 1, pp. 25-40, 2000.

[3] G. Murphy and H. Nagase, "Progress in matrix metalloproteinase research," Molecular Aspects of Medicine, vol. 29, no. 5, pp. 290-308, 2008.

[4] W. Borth, " $\alpha 2$-Macroglobulin, a multifunctional binding protein with targeting characteristics," The FASEB Journal, vol. 6, no. 15 , pp. 3345-3353, 1992. 
[5] B. R. Binder, G. Christ, F. Gruber et al., "Plasminogen activator inhibitor 1: physiological and pathophysiological roles," News in Physiological Sciences, vol. 17, no. 2, pp. 56-61, 2002.

[6] G. Murphy, "Tissue inhibitors of metalloproteinases," Genome Biology, vol. 12, no. 11, article 233, 2011.

[7] G. Murphy, "The ADAMs: signalling scissors in the tumour microenvironment," Nature Reviews Cancer, vol. 8, no. 12, pp. 929-941, 2008.

[8] A. P. Lillis, L. B. Van Duyn, J. E. Murphy-Ullrich, and D. K. Strickland, "LDL receptor-related protein 1: unique tissuespecific functions revealed by selective gene knockout studies," Physiological Reviews, vol. 88, no. 3, pp. 887-918, 2008.

[9] K. Danø, P. A. Andreasen, J. Grøndahl-Hansen, P. Kristensen, L. S. Nielsen, and L. Skriver, "Plasminogen activators, tissue degradation, and cancer," Advances in Cancer Research, vol. 44, pp. 139-266, 1985.

[10] E. I. Deryugina and J. P. Quigley, "Cell surface remodeling by plasmin: a new function for an old enzyme," Journal of Biomedicine and Biotechnology, vol. 2012, Article ID 564259, 21 pages, 2012.

[11] V. Ellis, T.-C. Wun, N. Behrendt, E. Ronne, and K. Dano, "Inhibition of receptor-bound urokinase by plasminogen-activator inhibitors," The Journal of Biological Chemistry, vol. 265, no. 17, pp. 9904-9908, 1990.

[12] S. M. Kanse, C. Kost, O. G. Wilhelm, P. A. Andreasen, and K. T. Preissner, "The urokinase receptor is a major vitronectin-binding protein on endothelial cells," Experimental Cell Research, vol. 224, no. 2, pp. 344-353, 1996.

[13] R.-P. Czekay, K. Aertgeerts, S. A. Curriden, and D. J. Loskutoff, "Plasminogen activator inhibitor-1 detaches cells from extracellular matrices by inactivating integrins," Journal of Cell Biology, vol. 160, no. 5, pp. 781-791, 2003.

[14] K. Bajou, A. Noël, R. D. Gerard et al., "Absence of host plasminogen activator inhibitor 1 prevents cancer invasion and vascularization," Nature Medicine, vol. 4, no. 8, pp. 923-928, 1998.

[15] K. Kessenbrock, V. Plaks, and Z. Werb, "Matrix metalloproteinases: regulators of the tumor microenvironment," Cell, vol. 141, no. 1, pp. 52-67, 2010.

[16] H. Hua, M. Li, T. Luo, Y. Yin, and Y. Jiang, "Matrix metalloproteinases in tumorigenesis: an evolving paradigm," Cellular and Molecular Life Sciences, vol. 68, no. 23, pp. 3853-3868, 2011.

[17] D. Bourboulia and W. G. Stetler-Stevenson, "Matrix metalloproteinases (MMPs) and tissue inhibitors of metalloproteinases (TIMPs): positive and negative regulators in tumor cell adhesion," Seminars in Cancer Biology, vol. 20, no. 3, pp. 161-168, 2010.

[18] H. Nagase, R. Visse, and G. Murphy, "Structure and function of matrix metalloproteinases and TIMPs," Cardiovascular Research, vol. 69, no. 3, pp. 562-573, 2006.

[19] A. H. Baker, D. R. Edwards, and G. Murphy, "Metalloproteinase inhibitors: biological actions and therapeutic opportunities," Journal of Cell Science, vol. 115, no. 19, pp. 3719-3727, 2002.

[20] K. Brew and H. Nagase, "The tissue inhibitors of metalloproteinases (TIMPs): an ancient family with structural and functional diversity," Biochimica et Biophysica Acta, vol. 1803, no. 1, pp. 55-71, 2010.

[21] Y. Nishida, H. Miyamori, E. W. Thompson, T. Takino, Y. Endo, and H. Sato, "Activation of matrix metalloproteinase-2 (MMP2) by membrane type 1 matrix metalloproteinase through an artificial receptor for ProMMP-2 generates active MMP-2," Cancer Research, vol. 68, no. 21, pp. 9096-9104, 2008.
[22] R. Chirco, X.-W. Liu, K.-K. Jung, and H.-R. C. Kim, "Novel functions of TIMPs in cell signaling," Cancer and Metastasis Reviews, vol. 25, no. 1, pp. 99-113, 2006.

[23] W. G. Stetler-Stevenson, "Tissue inhibitors of metalloproteinases in cell signaling: metalloproteinase-independent biological activities," Science Signaling, vol. 1, no. 27, article re6, 2008.

[24] E. Lambert, L. Bridoux, J. Devy et al., "TIMP-1 binding to proMMP-9/CD44 complex localized at the cell surface promotes erythroid cell survival," International Journal of Biochemistry and Cell Biology, vol. 41, no. 5, pp. 1102-1115, 2009.

[25] L. Bridoux, N. Etique, E. Lambert et al., "A crucial role for Lyn in TIMP-1 erythroid cell survival signalling pathway," FEBS Letters, vol. 587, no. 10, pp. 1524-1528, 2013.

[26] K.-K. Jung, X.-W. Liu, R. Chirco, R. Fridman, and H.-R. C. Kim, "Identification of CD63 as a tissue inhibitor of metalloproteinase-1 interacting cell surface protein," The EMBO Journal, vol. 25, no. 17, pp. 3934-3942, 2006.

[27] Y. Xia, N. Yeddula, M. Leblanc et al., "Reduced cell proliferation by IKK2 depletion in a mouse lung-cancer model," Nature Cell Biology, vol. 14, no. 3, pp. 257-265, 2012.

[28] J. Herz and D. K. Strickland, "LRP: a multifunctional scavenger and signaling receptor," The Journal of Clinical Investigation, vol. 108, no. 6, pp. 779-784, 2001.

[29] D. K. Strickland, J. D. Ashcom, S. Williams, W. H. Burgess, M. Migliorini, and W. Scott Argraves, "Sequence identity between the $\alpha 2$-macroglobulin receptor and low density lipoprotein receptor-related protein suggests that this molecule is a multifunctional receptor," The Journal of Biological Chemistry, vol. 265, no. 29, pp. 17401-17404, 1990.

[30] J. Stebbing, P. Savage, S. Patterson, and B. Gazzard, "All for CD91 and CD91 for all," Journal of Antimicrobial Chemotherapy, vol. 53, no. 1, pp. 1-3, 2004.

[31] J. Herz, D. E. Clouthier, and R. E. Hammer, "LDL receptorrelated protein internalizes and degrades UPA-PAI-1 complexes and is essential for embryo implantation," Cell, vol. 71, no. 3, pp. 411-421, 1992.

[32] T. Kristensen, S. K. Moestrup, J. Gliemann, L. Bendtsen, O. Sand, and L. Sottrup-Jensen, "Evidence that the newly cloned low-density-lipoprotein receptor related protein (LRP) is the $\alpha 2$-macroglobulin receptor," FEBS Letters, vol. 276, no. 1-2, pp. 151-155, 1990.

[33] P. A. Morton, D. A. Owensby, B. E. Sobel, and A. L. Schwartz, "Catabolism of tissue-type plasminogen activator by the human hepatoma cell line Hep G2. Modulation by plasminogen activator inhibitor type 1," The Journal of Biological Chemistry, vol. 264, no. 13, pp. 7228-7235, 1989.

[34] G. Bu, P. A. Morton, and A. L. Schwartz, "Identification and partial characterization by chemical cross-linking of a binding protein for tissue-type plasminogen activator ( $\mathrm{t}-\mathrm{PA}$ ) on rat hepatoma cells: a plasminogen activator inhibitor type 1independent t-PA receptor," The Journal of Biological Chemistry, vol. 267, no. 22, pp. 15595-15602, 1992.

[35] G. Bu, S. Williams, D. K. Strickland, and A. L. Schwartz, "Low density lipoprotein receptor-related protein $/ \alpha 2$-macroglobulin receptor is an hepatic receptor for tissue-type plasminogen activator," Proceedings of the National Academy of Sciences of the United States of America, vol. 89, no. 16, pp. 7427-7431, 1992.

[36] K. Orth, E. L. Madison, M.-J. Gething, J. F. Sambrook, and J. Herz, "Complexes of tissue-type plasminogen activator and its serpin inhibitor plasminogen-activator inhibitor type 1 are 
internalized by means of the low density lipoprotein receptorrelated protein $/ \alpha 2$-macroglobulin receptor," Proceedings of the National Academy of Sciences of the United States of America, vol. 89, no. 16, pp. 7422-7426, 1992.

[37] K. Orth, T. Willnow, J. Herz, M. J. Gething, and J. Sambrook, "Low density lipoprotein receptor-related protein is necessary for the internalization of both tissue-type plasminogen activator-inhibitor complexes and free tissue-type plasminogen activator," The Journal of Biological Chemistry, vol. 269, no. 33, pp. 21117-21122, 1994.

[38] A. Nykjaer, C. M. Petersen, B. Moller et al., "Purified $\alpha 2$ macroglobulin receptor/LDL receptor-related protein binds urokinase plasminogen activator inhibitor type-1 complex. Evidence that the $\alpha 2$-macroglobulin receptor mediates cellular degradation of urokinase receptor-bound complexes," The Journal of Biological Chemistry, vol. 267, no. 21, pp. 14543-14546, 1992.

[39] D. Croucher, D. N. Saunders, and M. Ranson, "The urokinase/PAI-2 complex: a new high affinity ligand for the endocytosis receptor low density lipoprotein receptorrelated protein," The Journal of Biological Chemistry, vol. 281, no. 15, pp. 10206-10213, 2006.

[40] M. Z. Kounnas, J. Henkin, W. S. Argraves, and D. K. Strickland, "Low density lipoprotein receptor-related protein $/ \alpha 2$ macroglobulin receptor mediates cellular uptake of prourokinase," The Journal of Biological Chemistry, vol. 268, no. 29, pp. 21862-21867, 1993.

[41] S. Stefansson, S. Muhammad, X.-F. Cheng, F. D. Battey, D. K. Strickland, and D. A. Lawrence, "Plasminogen activator inhibitor-1 contains a cryptic high affinity binding site for the low density lipoprotein receptor-related protein," The Journal of Biological Chemistry, vol. 273, no. 11, pp. 6358-6366, 1998.

[42] M. V. Cubellis, P. Andreasen, P. Ragno, M. Mayer, K. Dano, and F. Blasi, "Accessibility of receptor-bound urokinase to type1 plasminogen activator inhibitor," Proceedings of the National Academy of Sciences of the United States of America, vol. 86, no. 13, pp. 4828-4832, 1989.

[43] M. V. Cubellis, T.-C. Wun, and F. Blasi, "Receptor-mediated internalization and degradation of urokinase is caused by its specific inhibitor PAI-1," The EMBO Journal, vol. 9, no. 4, pp. 1079-1085, 1990.

[44] A. Nykjaer, M. Conese, E. I. Christensen et al., "Recycling of the urokinase receptor upon internalization of the uPA:serpin complexes," The EMBO Journal, vol. 16, no. 10, pp. 2610-2620, 1997.

[45] J.-C. Zhang, R. Sakthivel, D. Kniss, C. H. Graham, D. K. Strickland, and K. R. McCrae, "The low density lipoprotein receptor-related protein $/ \alpha 2$-macroglobulin receptor regulates cell surface plasminogen activator activity on human trophoblast cells," The Journal of Biological Chemistry, vol. 273, no. 48, pp. 32273-32280, 1998.

[46] R.-P. Czekay, T. A. Kuemmel, R. A. Orlando, and M. G. Farquhar, "Direct binding of occupied urokinase receptor (uPAR) to LDL receptor-related protein is required for endocytosis of UPAR and regulation of cell surface urokinase activity," Molecular Biology of the Cell, vol. 12, no. 5, pp. 1467-1479, 2001.

[47] B. Chazaud, R. Ricoux, C. Christov, A. Plonquet, R. K. Gherardi, and G. Barlovatz-Meimon, "Promigratory effect of plasminogen activator inhibitor-1 on invasive breast cancer cell populations," American Journal of Pathology, vol. 160, no. 1, pp. 237-246, 2002.
[48] H. Emonard, G. Bellon, P. de Diesbach, M. Mettlen, W. Hornebeck, and P. J. Courtoy, "Regulation of matrix metalloproteinase (MMP) activity by the low-density lipoprotein receptorrelated protein (LRP). A new function for an 'old friend"' Biochimie, vol. 87, no. 3-4, pp. 369-376, 2005.

[49] Z. Yang, D. K. Strickland, and P. Bornstein, "Extracellular matrix metalloproteinase 2 levels are regulated by the low density lipoprotein-related scavenger receptor and thrombospondin 2," The Journal of Biological Chemistry, vol. 276, no. 11, pp. 84038408, 2001.

[50] H. Emonard, G. Bellon, L. Troeberg et al., "Low density lipoprotein receptor-related protein mediates endocytic clearance of pro-MMP-2-TIMP-2 complex through a thrombospondinindependent mechanism," The Journal of Biological Chemistry, vol. 279, no. 52, pp. 54944-54951, 2004.

[51] O. Y. Barmina, H. W. Walling, G. J. Fiacco et al., "Collagenase3 binds to a specific receptor and requires the low density lipoprotein receptor-related protein for internalization," The Journal of Biological Chemistry, vol. 274, no. 42, pp. 3008730093, 1999.

[52] E. Hahn-Dantona, J. F. Ruiz, P. Bornstein, and D. K. Strickland, "The low density lipoprotein receptor-related protein modulates levels of matrix metalloproteinase 9 (MMP-9) by mediating its cellular catabolism," The Journal of Biological Chemistry, vol. 276, no. 18, pp. 15498-15503, 2001.

[53] P. E. Van den Steen, I. Van Aelst, V. Hvidberg et al., "The hemopexin and O-glycosylated domains tune gelatinase B/MMP-9 bioavailability via inhibition and binding to cargo receptors," The Journal of Biological Chemistry, vol. 281, no. 27, pp. 18626-18637, 2006.

[54] L. Troeberg, K. Fushimi, R. Khokha, H. Emonard, P. Ghosh, and H. Nagase, "Calcium pentosan polysulfate is a multifaceted exosite inhibitor of aggrecanases," The FASEB Journal, vol. 22, no. 10, pp. 3515-3524, 2008.

[55] S. D. Scilabra, L. Troeberg, K. Yamamoto et al., "Differential regulation of extracellular tissue inhibitor of metalloproteinases-3 levels by cell membrane-bound and shed low density lipoprotein receptor-related protein 1," The Journal of Biological Chemistry, vol. 288, no. 1, pp. 332-342, 2013.

[56] U. Barash, V. Cohen-Kaplan, I. Dowek, R. D. Sanderson, N. Ilan, and I. Vlodavsky, "Proteoglycans in health and disease: new concepts for heparanase function in tumor progression and metastasis," FEBS Journal, vol. 277, no. 19, pp. 3890-3903, 2010.

[57] V. Vreys, N. Delande, Z. Zhang et al., "Cellular uptake of mammalian heparanase precursor involves low density lipoprotein receptor-related proteins, mannose 6-phosphate receptors, and heparan sulfate proteoglycans," The Journal of Biological Chemistry, vol. 280, no. 39, pp. 33141-33148, 2005.

[58] K. Yamamoto, L. Troeberg, S. D. Scilabra et al., "LRP-1-mediated endocytosis regulates extracellular activity of ADAMTS-5 in articular cartilage," The FASEB Journal, vol. 27, no. 2, pp. 511521, 2013.

[59] P. Briozzo, M. Morisset, F. Capony, C. Rougeot, and H. Rochefort, "In vitro degradation of extracellular matrix with M(r) 52,000 cathepsin D secreted by breast cancer cells," Cancer Research, vol. 48, no. 13, pp. 3688-3692, 1988.

[60] M. Beaujouin, C. Prébois, D. Derocq et al., "Pro-cathepsin D interacts with the extracellular domain of the $\beta$ chain of LRP1 and promotes LRP1-dependent fibroblast outgrowth," Journal of Cell Science, vol. 123, no. 19, pp. 3336-3346, 2010. 
[61] D. Derocq, C. Prébois, M. Beaujouin et al., "Cathepsin D is partly endocytosed by the LRP1 receptor and inhibits LRP1regulated intramembrane proteolysis," Oncogene, vol. 31, no. 26, pp. 3202-3212, 2012.

[62] P. May, E. Woldt, R. L. Matz, and P. Boucher, “The LDL receptorrelated protein (LRP) family: an old family of proteins with new physiological functions," Annals of Medicine, vol. 39, no. 3, pp. 219-228, 2007.

[63] S. Dedieu, B. Langlois, J. Devy et al., "LRP-1 silencing prevents malignant cell invasion despite increased pericellular proteolytic activities," Molecular and Cellular Biology, vol. 28, no. 9, pp. 2980-2995, 2008.

[64] B. Langlois, G. Perrot, C. Schneider et al., "LRP-1 promotes cancer cell invasion by supporting ERK and inhibiting JNK signaling pathways," PLoS ONE, vol. 5, no. 7, Article ID el1584, 2010.

[65] M. M. Hardy, J. Feder, R. A. Wolfe, and G. Bu, "Low density lipoprotein receptor-related protein modulates the expression of tissue-type plasminogen activator in human colon fibroblasts," The Journal of Biological Chemistry, vol. 272, no. 10, pp. 6812-6817, 1997.

[66] X. Wang, S.-R. Lee, K. Arai et al., "Lipoprotein receptormediated induction of matrix metalloproteinase by tissue plasminogen activator," Nature Medicine, vol. 9, no. 10, pp. 1313-1317, 2003.

[67] K. Hu, J. Yang, S. Tanaka, S. L. Gonias, W. M. Mars, and Y. Liu, "Tissue-type plasminogen activator acts as a cytokine that triggers intracellular signal transduction and induces matrix metalloproteinase-9 gene expression," The Journal of Biological Chemistry, vol. 281, no. 4, pp. 2120-2127, 2006.

[68] B. Fayard, F. Bianchi, J. Dey et al., “The serine protease inhibitor protease nexin-1 controls mammary cancer metastasis through LRP-1-mediated MMP-9 expression," Cancer Research, vol. 69, no. 14, pp. 5690-5698, 2009.

[69] L. C. Cáceres, G. R. Bonacci, M. C. Sánchez, and G. A. Chiabrando, "Activated $\alpha 2$ macroglobulin induces matrix metalloproteinase 9 expression by low-density lipoprotein receptorrelated protein 1 through MAPK-ERK1/2 and NF- $\kappa$ B activation in macrophage-derived cell lines," Journal of Cellular Biochemistry, vol. 111, no. 3, pp. 607-617, 2010.

[70] H. Song, Y. Li, J. Lee, A. L. Schwartz, and G. Bu, "Low-density lipoprotein receptor-related protein 1 promotes cancer cell migration and invasion by inducing the expression of matrix metalloproteinases 2 and 9," Cancer Research, vol. 69, no. 3, pp. 879-886, 2009.

[71] M. Hartmann, A. Herrlich, and P. Herrlich, "Who decides when to cleave an ectodomain?" Trends in Biochemical Sciences, vol. 38, no. 3, pp. 111-120, 2013.

[72] K. A. Quinn, V. J. Pye, Y.-P. Dai, C. N. Chesterman, and D. A. Owensby, "Characterization of the soluble form of the low density lipoprotein receptor-related protein (LRP)," Experimental Cell Research, vol. 251, no. 2, pp. 433-441, 1999.

[73] K. A. Quinn, P. G. Grimsley, Y.-P. Dai, M. Tapner, C. N. Chesterman, and D. A. Owensby, "Soluble low density lipoprotein receptor-related protein (LRP) circulates in human plasma," The Journal of Biological Chemistry, vol. 272, no. 38, pp. 2394623951, 1997.

[74] Q. Liu, J. Zhang, H. Tran et al., "LRP1 shedding in human brain: roles of ADAM10 and ADAM17," Molecular Neurodegeneration, vol. 4, no. 1, article 17, 2009.

[75] C. Selvais, L. D’Auria, D. Tyteca et al., "Cell cholesterol modulates metalloproteinase-dependent shedding of low-density lipoprotein receptor-related protein-1 (LRP-1) and clearance function," The FASEB Journal, vol. 25, no. 8, pp. 2770-2781, 2011.

[76] D. V. Rozanov, E. Hahn-Dantona, D. K. Strickland, and A. Y. Strongin, "The low density lipoprotein receptor-related protein LRP is regulated by membrane type- 1 matrix metalloproteinase (MT1-MMP) proteolysis in malignant cells," The Journal of Biological Chemistry, vol. 279, no. 6, pp. 4260-4268, 2004.

[77] R. Polavarapu, M. C. Gongora, H. Yi et al., “Tissue-type plasminogen activator-mediated shedding of astrocytic low-density lipoprotein receptor-related protein increases the permeability of the neurovascular unit," Blood, vol. 109, no. 8, pp. 3270-3278, 2007.

[78] C. A. F. von Arnim, A. Kinoshita, I. D. Peltan et al., "The low density lipoprotein receptor-related protein (LRP) is a novel $\beta$-secretase (BACE1) substrate," The Journal of Biological Chemistry, vol. 280, no. 18, pp. 17777-17785, 2005.

[79] J. An, C. Zhang, R. Polavarapu, X. Zhang, X. Zhang, and M. Yepes, "Tissue-type plasminogen activator and the low-density lipoprotein receptor related protein induce Akt phosphorylation in the ischemic brain," Blood, vol. 112, no. 7, pp. 2787-2794, 2008.

[80] P. G. Grimsley, K. A. Quinn, and D. A. Owensby, "Soluble low-density lipoprotein receptor-related protein," Trends in Cardiovascular Medicine, vol. 8, no. 8, pp. 363-368, 1998.

[81] M. Wygrecka, J. Wilhelm, E. Jablonska et al., "Shedding of lowdensity lipoprotein receptor-related protein-1 in acute respiratory distress syndrome," American Journal of Respiratory and Critical Care Medicine, vol. 184, no. 4, pp. 438-448, 2011.

[82] C. Selvais, H. P. Gaide Chevronnay, P. Lemoine et al., "Metalloproteinase-dependent shedding of low-density lipoprotein receptor-related protein-1 ectodomain decreases endocytic clearance of endometrial matrix metalloproteinase-2 and -9 at menstruation," Endocrinology, vol. 150, no. 8, pp. 3792-3799, 2009.

[83] G. Perrot, B. Langlois, J. Devy et al., "LRP-1:CD44, identification of a new cell surface complex regulating tumor cell adhesion," Molecular and Cellular Biology, vol. 32, no. 16, pp. 3293-3307, 2012. 

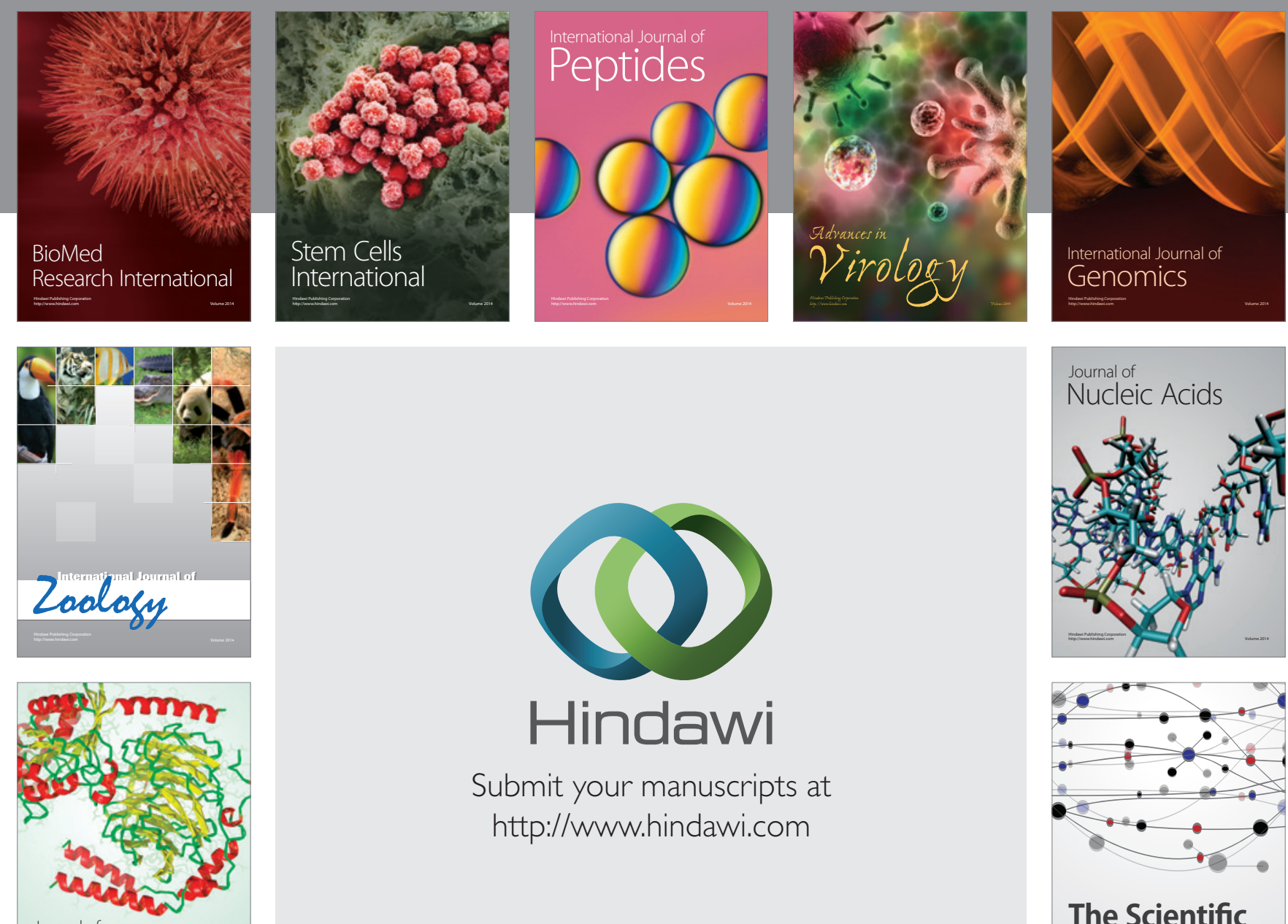

Submit your manuscripts at

http://www.hindawi.com

Journal of
Signal Transduction
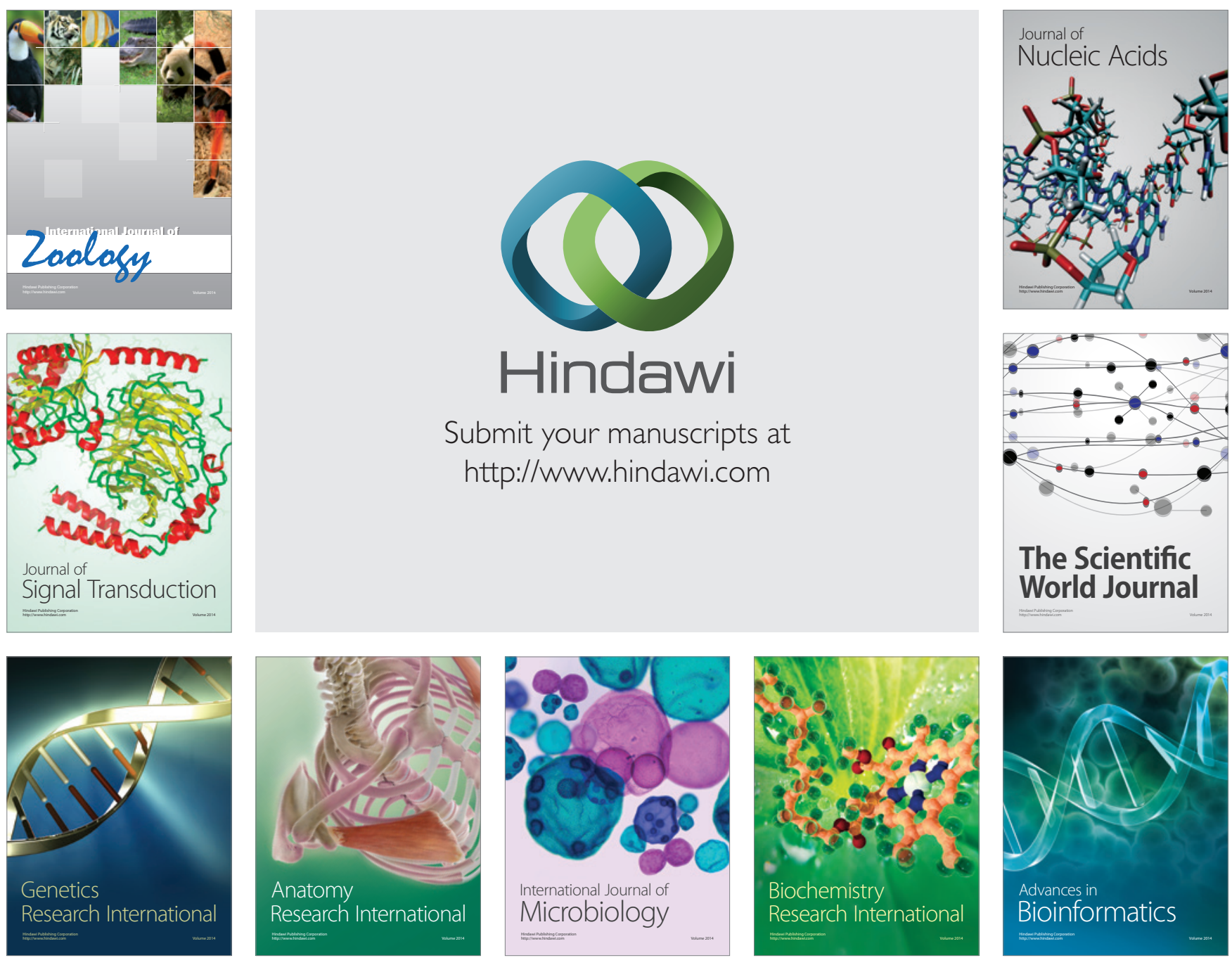

The Scientific World Journal
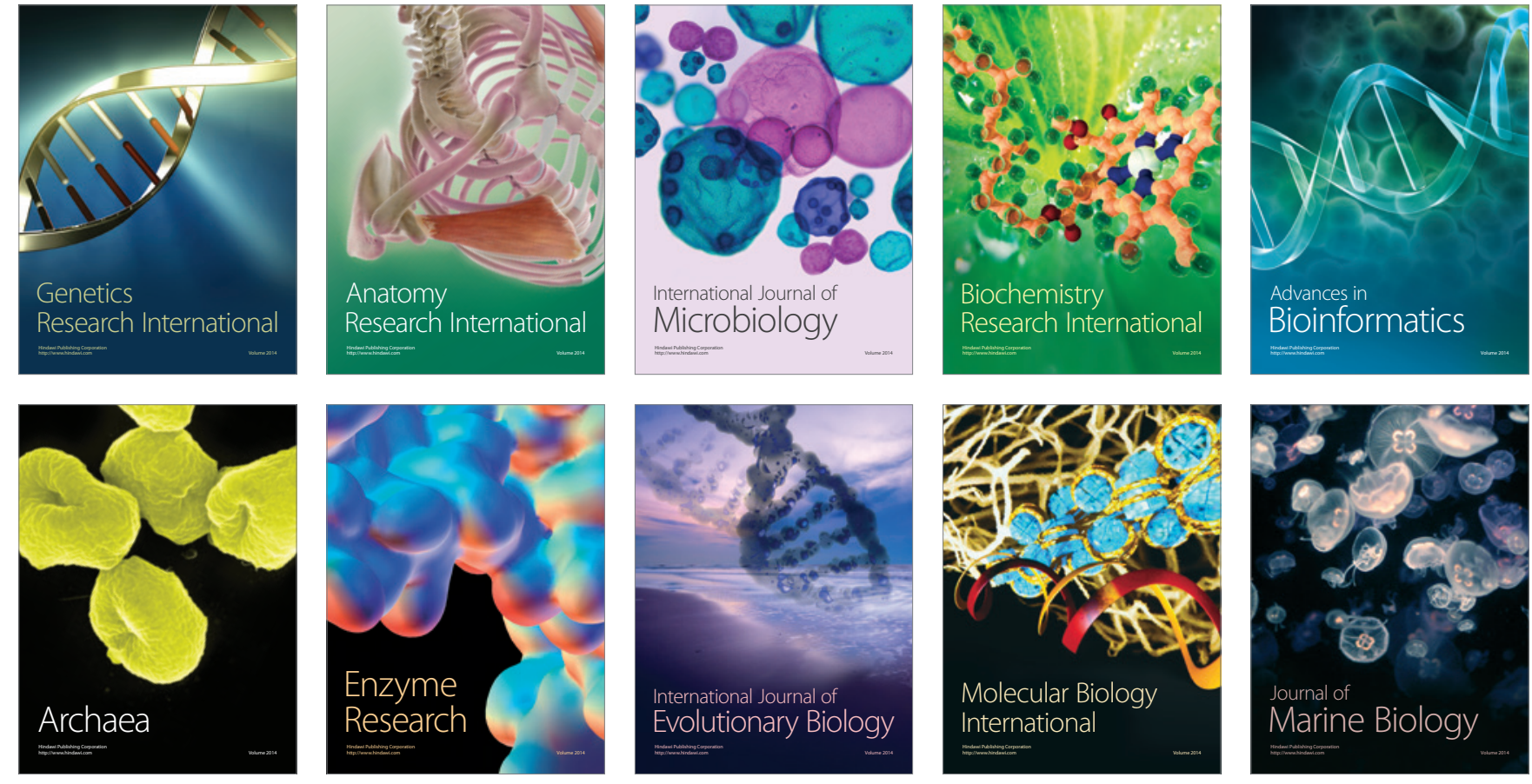